International Journal of Electrical and Power Engineering 6 (1): 26-31, 2012

ISSN: 1990-7958

(C) Medwell Journals, 2012

\title{
Study and Analysis of Energy Conversion using Solar Cell
}

\author{
M. Nazrul Islam, Kh. Assaduzzaman and Mahbubul Hoq \\ Institute of Electronics, Atomic Energy Research Establishment, \\ Bangladesh Atomic Energy Commission, Savar, Dhaka, Bangladesh
}

\begin{abstract}
In this study, a comphrehensive study on electronic behaviour, economics and social impacts of energy conversion from solar cell have been presented. A solar cell or photovoltaic cell is a device that converts light energy into electrical energy. Sometimes, the term solar cell is reserved for devices intended specifically to capture energy from sunlight while the term photovoltaic cell is used when the light source is unspecified. Fundamentally, the device needs to fulfill only two functions: photogeneration of charge carriers (electrons and holes) in a light-absorbing material and separation of the charge carriers to a conductive contact that will transmit the electricity. This conversion is useful for solar home system, water pumping and small business.
\end{abstract}

Key words: PV effect, solar radiation, solar cell, battery charger, inverter, Bangladesh

\section{INTRODUCTION}

The principles of semiconductor (Markvart, 1994) physics are best illustrated by the example of silicon, group 4 elemental semiconductors. The silicon crystal forms the so-called diamond lattice where each atom has four nearest neighbours at the vertices of tetrahedron. This crystal structures has profound effect on the electronic and optical properties of the semiconductor (Table 1).

In separation, there is electron surplus in the n-type material and hole surplus in the p-type. When the two pieces are brought into contact, electrons from the $\mathrm{n}$ region near the interface diffuse into the $\mathrm{p}$ side, leaving behind a layer which is positively charged by the donors. Similarly, holes diffuse in the opposite direction, leaving behind a negatively charged layer stripped of holes.

The resulting junction region then contains practically no mobile charge carriers (Fig. 1) and he fixed charges of the dopant atoms create a potential berried acting against a further flow of electrons and holes.

\begin{tabular}{lcc}
$\begin{array}{l}\text { Table 1: Energy gaps of principal semiconductors for } \\
\text { applications (gap values given at room temperature) }\end{array}$ & photovoltaic \\
\hline Materials & Energy gap (eV) & Types of gap \\
\hline Crystalline Si & 1.120 & Indirect \\
Amorphous Si & 1.750 & Direct \\
CulnSe $_{2}$ & 1.050 & Direct \\
$\mathrm{CdTe}$ & 1.450 & Direct \\
$\mathrm{GaAs}$ & 1.420 & Direct \\
$\mathrm{InP}$ & 1.340 & Direct \\
\hline
\end{tabular}

The electric field in the junction pulls the electrons and holes in opposite directions. In mathematical terms, the I-V characteristic of a diode is given by the Shockley equation:

$$
I=I_{0}\left[\exp \left(\frac{q V}{k T}-1\right)\right]
$$

Where:

$\mathrm{I}=$ Current

$\mathrm{V}=$ Voltage

$\mathrm{k}=$ Boltzmann constant

$\mathrm{q}=$ Magnitude of the electron charge

$\mathrm{T}=$ The absolute temperature

To understand the electronic behaviour of a solar cell, it is useful to create a model which is electrically equivalent and is based on discrete electrical components whose behaviour is well known. An ideal solar cell may be modelled by a current source in parallel with a diode. In

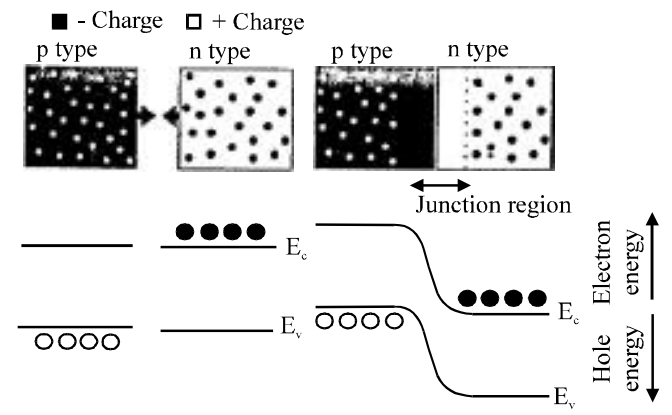

Fig. 1: Diagram of $\mathrm{p}-\mathrm{n}$ junction formation and the resulting band structure

Corresponding Author: M. Nazrul Islam, Institute of Electronics, Atomic Energy Research Establishment, Bangladesh Atomic Energy Commission, Savar, Dhaka, Bangladesh 
practice, no solar cell is ideal so a shunt resistance and a series resistance component are added to the model. The result is the equivalent circuit of a solar cell shown in Fig. 2. Also in Fig. 3 and 4, there is the schematic representation of a solar cell for use in circuit diagram.

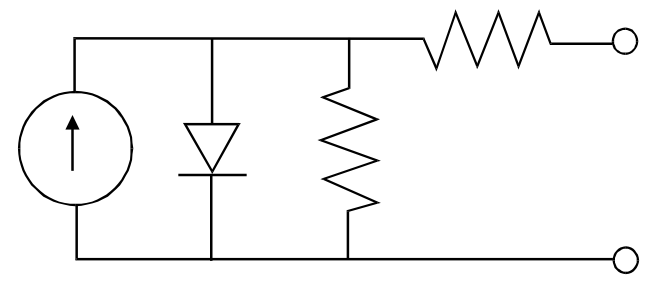

Fig. 2: Equivalent circuit of a solar cell

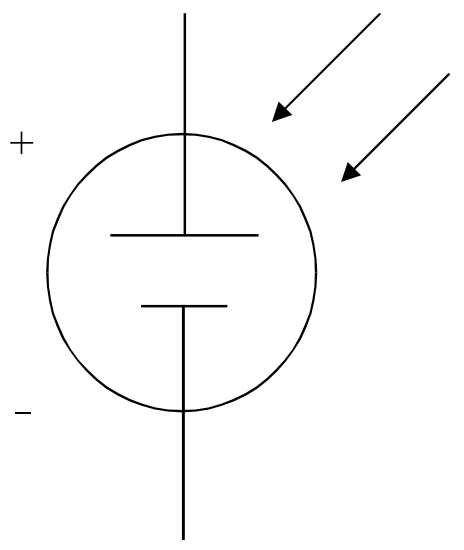

Fig. 3: Schematic symbol of a solar cell

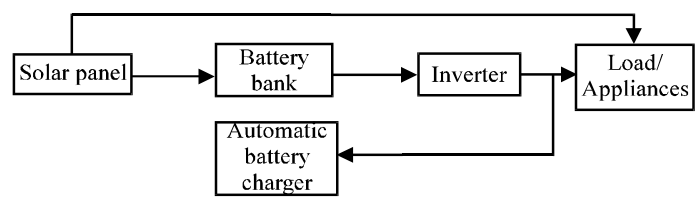

Fig. 4: The proposed complete solar system

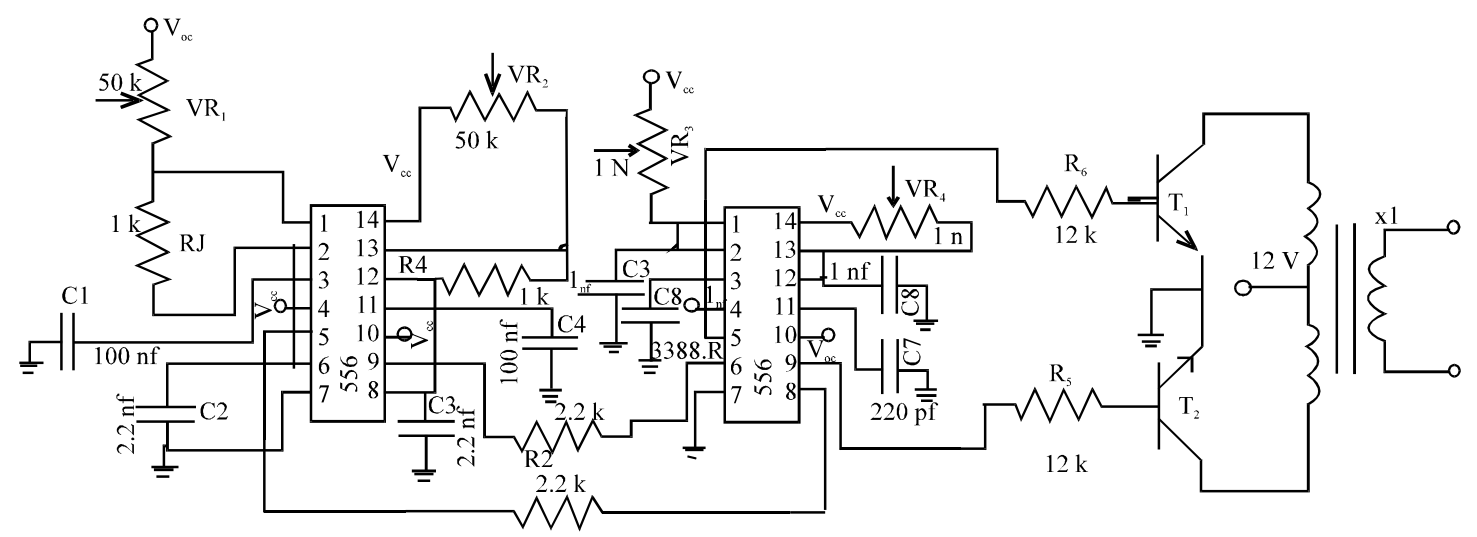

Fig. 6: The complete schematic diagram of the inverter circuit 


\section{RESULTS AND DISCUSSION}

Light absorption by a semiconductor: Photovoltaic energy conversion relies on the quantum nature of light whereby we perceive light as a flux of particles, photons which carry the energy (Fig. 7; Markvart, 1994).

$$
\operatorname{eph}(\lambda)=\frac{h \mathrm{c}}{\lambda}
$$

Where:

$\mathrm{h}=$ Planck constant

$\mathrm{c}=$ The speed of light

$\lambda=$ The wavelength of light

Each semiconductor is therefore restricted to converting only a part of the solar spectrum. Using Eq. 2, the spectrum has been plotted here in terms of the incident photon flux as a function of photon energy. The shaded area represents the photon flux that can be converted by a silicon cell about two-third of the total flux (Fig. 8).

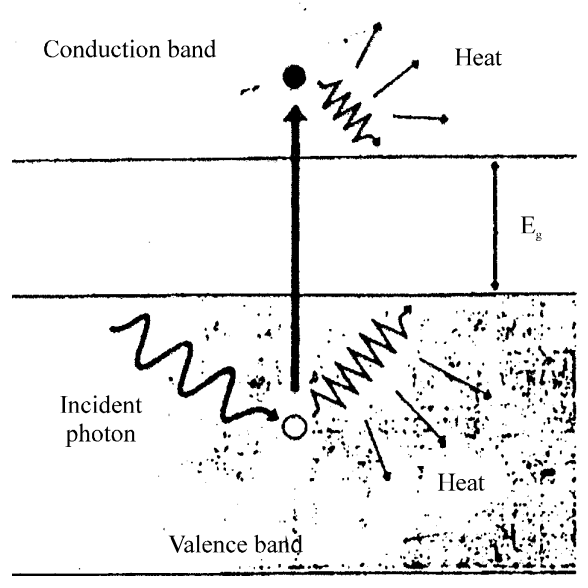

Fig. 7: The generation of electron-hole pairs by light

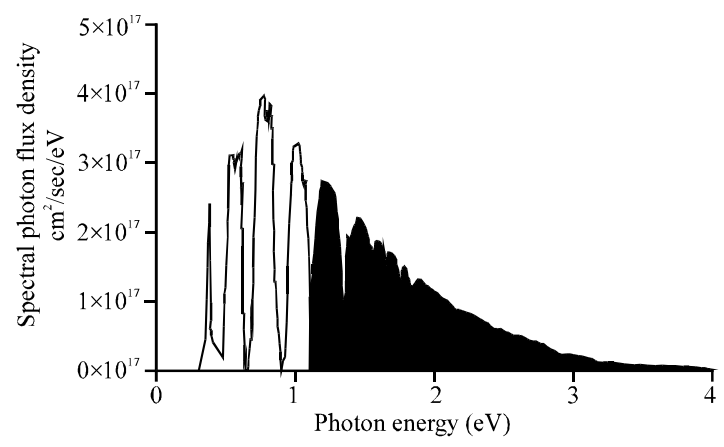

Fig. 8: Photon flux utilize by a silicon solar cell
Researchers can make some rough estimates of the magnitude of electrical power that can be produced. Neglecting losses, each photon then contributes one electron charge to the generation current. The electric current is then equal to:

$$
\mathrm{I}_{1}=\mathrm{qNA}
$$

Where:

$\mathrm{q}=$ The charge of electron

$\mathrm{N}=$ The number of protons in the highlighted area of the spectrum

$\mathrm{A}=$ The surface area of the semiconductor that is exposed to light

Solar radiation falling on the surface of the earth in the visible and near infrared wavelength range $(0.3-2.0 \mu \mathrm{m})$ is measured on the ground by means of pyranometer that provides good time resolution. With the fine time resolution, a detailed knowledge of the variations of solar radiation over areas of earth's surface is also important because local climates are greatly influenced by the coastlines, mountains, water bodies and large cities. Therefore, proper processing of satellite data provides a wealth of information useful in the production of solar atlases, particularly for those areas where no traditional observations are available. These satellites data also make it possible to investigate spatially small-scale variations of available solar energy, knowledge of which is needed for planning purposes (Ali et al., 2005).

A good number of studies clearly demonstrate the satellite data can be used successfully for mapping of the global radiation at ground level with a reasonably acceptable error (Cano et al., 1986; Diabate et al., 1988; Gautier et al., 1980; Tarpley, 1997).

The solar cell: Figure 9 shows the diagram of a silicon cell, the typical solar cell in use today. The electrical current generator in the semiconductor is extracted by contacts to the front and rear of the cell. The top contact

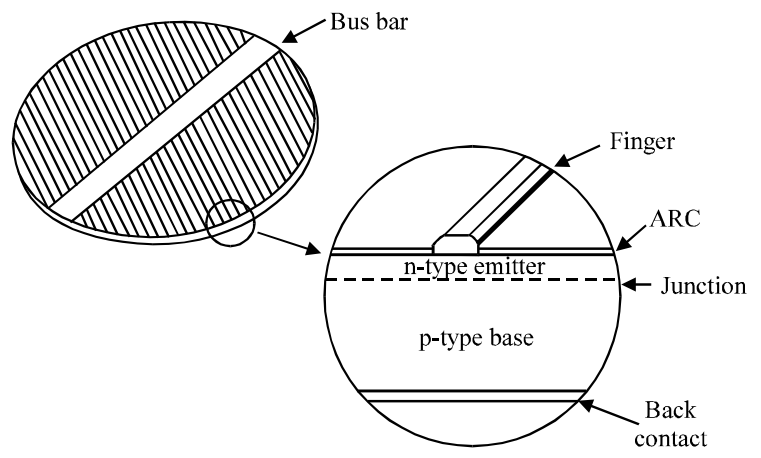

Fig. 9: The silicon solar cell 
Int. J. Elec. Power Eng., 6 (1): 26-31, 2012

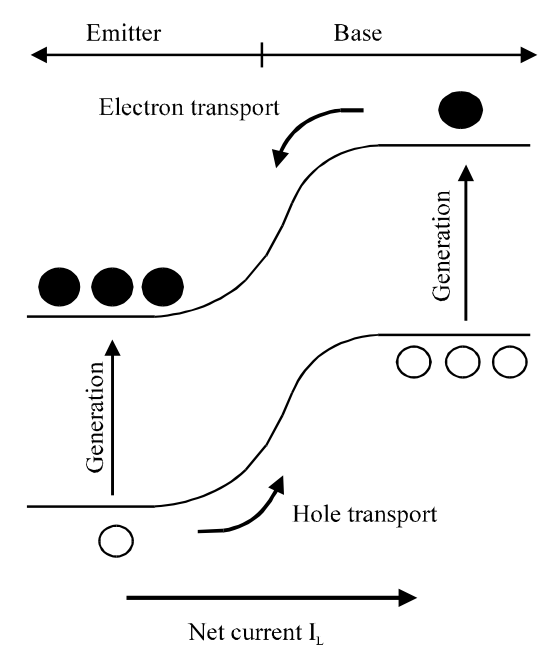

Fig. 10: Currents in a p-n junction under illumination

structure which must allow light to pass through is made in the form of widely spaced thin metal strips (usually called fingers) that supply current to a larger bus bar. The cell is covered with a thin layer of dielectric material the antireflection coating or ARC to minimize light reflection from the top surface (Fig. 9).

Figure 10 shows the band diagram of the semiconductor section under illumination. Light generates electron hole pairs in both sides of the function in the n-type emitter and in the p-type base. The generated minority carries-electrons from the base and holes from the emitter then diffuse to the junction and are swept away by the electric field, thus producing electric current across the device. Note that the electric currents of the electrons and holes reinforce each other since these particles carry opposite charges. The p-n junction therefore, separates the carriers with opposite charge and transforms the generation current $\mathrm{I}_{1}$ between the bands into an electric current across the p-n function.

$$
\mathrm{I}=\mathrm{I}_{1}-\mathrm{I}_{0}\left[\exp \left(\frac{\mathrm{qV}}{\mathrm{kT}}\right)-1\right]
$$

One is the short-circuit current $\mathrm{I}_{\mathrm{AC}}$ which as we noted is simply the light generated current $\mathrm{I}_{\mathrm{t}}$. The second is the open circuit voltage $V_{o c}$ obtained by setting $I=0$ :

$$
\mathrm{V}_{\mathrm{oc}}=\frac{\mathrm{kT}}{\mathrm{q}} \ln \left(\frac{\mathrm{I}_{1}}{\mathrm{I}_{\mathrm{o}}}+1\right)
$$

It is worthwhile to examine this equation in more detail. Both $\mathrm{I}_{1}$ and $\mathrm{I}_{0}$ depend on the structure of the device. However, it is the value of $I_{0}$ which can vary by many

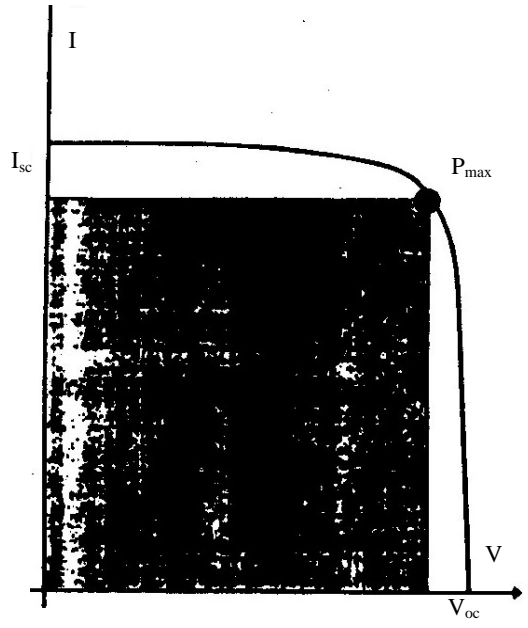

Fig. 11: I-V characteristic of a solar cell with the maximum power point

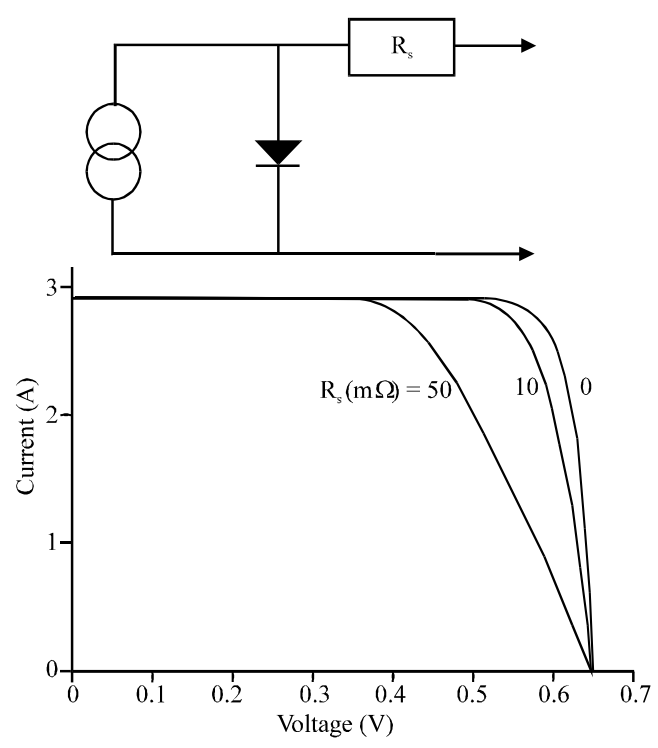

Fig. 12: The series resistance and its effect on the I-V characteristic of a solar cell

orders of magnitude depending on the device geometry ad processing that determines the open circuit voltage in practical devices. $P_{\max } V_{m} I_{m}=F F V_{o c} I_{s c}$ where $V_{m}$ and $V_{m}$ are the voltage and current at the maximum power point. No power is generated under shout or open circuit. The maximum power $\mathrm{P}_{\max }$ produced by the device is produced at a point on the characteristic where the product IV is maximum. This is shown graphically in Fig. 11 where the position if the maximum power point represents the largest area of the rectangle shown (Fig. 12).

Economics: In determining the economic (Howell et al., 1982) feasibility of any system alternative, the designer 

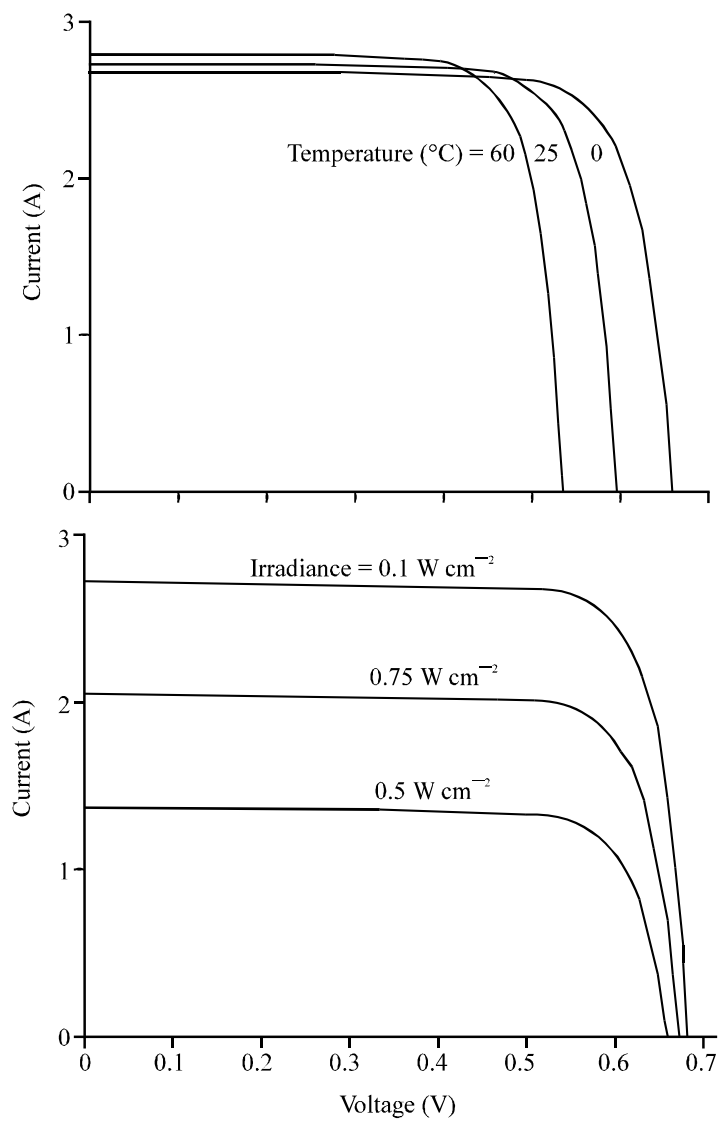

Fig. 13: Temperature and irradiance dependence of the I$\mathrm{V}$ characteristic of a solar cell

must know the present cost of money (interest rate) and desired payback period for the equipment as well as the cost of equipment, fuels, labor, maintenanace, etc. In most cases, these figures are available. However, when evaluating a technically new product such as a solar conversion system, cost data may be neither readily available nor accurate. In performing the analysis, two questions of importance have to do with what cost per unit area of solar collector can be economically justified and whether collectors are available at that price.

A solar cell may operate over a wide range of voltages (V) and currents (I). By increasing the resistive load on an irradiated cell continuously from zero (a short circuit) to a very high value (an open circuit) one can determine the maximum power point that is the load for which the cell can deliver maximum electrical power at that level of irradiation. $V_{m} \times I_{m}=P_{m}$ in watts (Fig. 13).

Energy conversion efficiency: A solar cell's energy conversion efficiency $(\eta$, eta) is the percentage of power converted (from absorbed light to electrical energy) and collected when a solar cell is connected to an electrical circuit. This term is calculated using the ratio of $P_{m}$ divided by the input light irradiance under standard test conditions $\left(\mathrm{E}\right.$, in $\left.\mathrm{W} \mathrm{m}^{-2}\right)$ and the surface area of the solar cell $\left(\mathrm{A}_{\mathrm{c}}\right.$ in $\left.\mathrm{m}^{2}\right)$ :

$$
\eta=\frac{P_{m}}{E \times A_{c}}
$$

Fill factor: Another defining term in the overall behavior of a solar cell is the Fill Factor (FF). This is the ratio of the maximum power point divided by the open circuit voltage $\left(\mathrm{V}_{\mathrm{oc}}\right)$ and the short circuit current $\left(\mathrm{I}_{\mathrm{sc}}\right)$ :

$$
\mathrm{FF}=\frac{\mathrm{P}_{\mathrm{m}}}{\mathrm{V}_{\mathrm{oc}} \times \mathrm{I}_{\mathrm{sc}}}=\frac{\eta \times \mathrm{A}_{\mathrm{c}} \times \mathrm{E}}{\mathrm{V}_{\mathrm{oc}} \times \mathrm{I}_{\mathrm{sc}}}
$$

Social impacts: The solar electrification (Mondal and Rehling, 2006) is providing direct and indirec benefits to the users of the systems with many implication of a permanent nature. Reduction of kerosene usage is the main impact of the solar home system that results less pollution, less darkness, less hassle and in addition less clearing kerosene lamps as well. People who are engaged with small businees using traditional fuels now switch to solar light that results the more development of their business than before. Women and children are benefitted from the quality of light for household works and studing in the evenings. Solar electrification of the premises is also added to the overall comfort and satisfaction of the remote consumers.

\section{CONCLUSION}

The solar resource is usually viewed as low-intensity energy when compared with the conventional energy sources of today (fossil and nuclear fuels). However, when the local solar input at the ground is compared to the energy currently generated or used locally, the solar resource provides a surprisingly good match even in today's energy-rich society. If the possibility of satellite solar collection system is accepted then the solar resource, both in rate and longevity becomes essentially unbounded.

Solar energy is most attractive for applications involving low temperatures and fairly uniform seasonal demand, locations that have good insolation and areas where conventional energy is expensive. Besides this, domestic water heating, space heating, swimming pool heaters and car washing etc. would be benefitted by utilizing the resource. 


\section{REFERENCES}

Ali, M.S., S.K. Aditya, A.H. Howlader and R.K. Mazumder, 2005. Performances of statistical models for measuring solar radiation from satellite data. $\mathrm{J}$. Bangladesh Electron. Soc., 5: 101-106.

Cano, D., J.M. Monget, M. Albuisson, H. Gullard, N. Regas and L. Wald, 1986. A method for the determination of the global solar radiation from mateorological satallite data. Solar Energy, 37: 31-39.

Diabate, L., H. Demarcq, N. Michaud-Regas and L. Wald, 1988. Estimating incident solar radiation at the surface from images of the earth transmitted by geostationary satellites: The heliosat project. Int. J. Solar Energy, 5: 261-278.

Gautier, C., G. Diak and S. Masse, 1980. A simple physical model to estimate incident solar radiation at the surface from GOES satellite data. J. Applied Meteorol., 19: 1005-1012.
Howell, J.R., R.B. Bannerot and C. Gary, 1982. Solar Thermal Energy Systems. McGraw-Hill Book Company, Vliet.

Markvart, T., 1994. Solar Electricity. John Wiley and Sons, UK.

Mondal, A.H. and U. Rehling, 2006. Social impacts of solar home system application. Proceedings of the 4th International Conference on Electrical Engineering and 2nd APM, January 26-28, 2006, IEB, Dhaka, pp: 64-64.

Sharma, M.C., 1987. Transistors and Thyristors Made Easy. 1st Edn., BPB Publications, Delhi, India, Pages: 261.

Tarpley, J.D., 1997. Estimating incident solar radiation at the surface from geostationary satellite data. J. Applied Meteorol., 18: 1172-1181. 